Ciência Florestal, Santa Maria, v. 24, n. 1, p. 47-58, jan.-mar., 2014 ISSN 0103-9954

\title{
LEVANTAMENTO FLORÍSTICO DO ESTRATO ARBÓREO DE TRÊS FRAGMENTOS DE FLORESTA CILIAR COMO SUBSÍDIO À RECOMPOSIÇÃO DA VEGETAÇÃO DO RIO CEDRO, MONTES CLAROS - MG
}

\author{
FLORISTIC SURVEY OF ARBOREAL STRATUM OF THREE FRAGMENTS OF RIPARIAN \\ FOREST AS A SUBSIDY TO ' RIO CEDRO’ VEGETATION RECOMPOSITION IN MONTES \\ CLAROS - MG
}

\author{
Maria Clara Oliveira Durães ${ }^{1}$ Nilza de Lima Pereira Sales ${ }^{2}$ Santos D’Ângelo Neto ${ }^{3}$ \\ Maria Auxiliadora Pereira Figueiredo ${ }^{4}$
}

\begin{abstract}
RESUMO
Os objetivos deste estudo foram conhecer a composição florística de três fragmentos de floresta ciliar do Rio Cedro, Montes Claros - MG e selecionar espécies para serem utilizadas na recomposição. Realizou-se o levantamento florístico, análise de similaridade e a classificação sucessional. Foram amostrados 356 indivíduos em três fragmentos, sendo: 99 no $1^{\circ}, 117$ no $2^{\circ}$ e 140 no $3^{\circ}$ com um total de 53 espécies, duas não identificadas, 46 gêneros e 22 famílias. $\mathrm{O} 1^{\circ}$ Fragmento apresentou a maior riqueza florística: 28 espécies, seguida pelo $2^{\circ}$ com 26 e o $3^{\circ} \mathrm{com} 25$. As famílias com maior número de indivíduos foram Fabaceae (111), Malvaceae (50), Arecaceae (45) e Anacardiaceae (32). A Fabaceae foi a família com maior número de espécies representas. Das análises, obteve-se um índice de similaridade de Sørensen para os Fragmentos: 1 e 2, 52,8\%, 2 e 3, 40\% e 1 e $333,3 \%$. Os valores maiores de riquezas de espécies pioneiras e secundárias iniciais caracterizam uma fase de transição da floresta pioneira, típica de estágio sucessional médio. Os fragmentos apresentam características da floresta estacional decidual, encontrando-se perturbados. Para a recomposição da floresta ciliar propôs-se a seleção de espécies de diferentes grupos ecológicos.
\end{abstract}

Palavras-chave: floresta ciliar; composição florística; conservação.

\begin{abstract}
The objectives of this study were to know the floristic composition of three fragments of riparian forest from Rio Cedro, Montes Claros, Minas Gerais state and select species to be used in its recomposition. It was done a floristic survey, similarity analysis and sucessional classification of species. We sampled 356 individuals in three fragments, and: 99 at the 1 st one, 117 at the 2nd one and 140 at the 3rd one with a total of 53 species, 2 unidentified, 46 genera and 22 families. The majority floristic wealth was found at the 1st fragment: 28 species, then at the 2 rd one with 26 last at the 3nd with 25 . The families with the highest number of individuals were Fabaceae (111), Malvaceae (50), Arecaceae (45), Anacardiaceae (32). The Fabaceae family showed the greatest number of species represented. By the tests, Sorensen's similarity rate was obtained for the fragments: 1 and 2, 52.8\%, 2 and 3,40\% and 1 and $333.3 \%$. The greatest wealth of pioneering species and secondary ones characterize an initial phase of transition from forest pioneering, typical of sucessional medium probation and show characteristics of seasonal decidual forest. The fragments studied are disrupted. In order to the recomposition of the riparian forest, a selection of species to be used in its recomposition and the combination of different ecological groups are proposed.
\end{abstract}

Keywords: riparian forest; floristic composition; conservation.

1 Bióloga, Msc., Professora de Gestão Ambiental, Instituto Federal Norte de Minas, Campus de Salinas, Fazenda Varginha, Km 02, Rod. Salinas/Taiobeiras, CEP 39560, Salinas (MG), Brasil. clarinhabio@bol.com.br

2 Engenheira Florestal, Dr., Professora do Departamento de Ciências Florestais, Instituto de Ciências Agrárias, Universidade Federal de Mina Gerais, Av. Universitária, 1000, Bairro Universitário, CEP 39404-006, Montes Claros (MG), Brasil.nsales@nca.ufmg.br

3 Engenheiro Agrônomo, Dr., Professor do Departamento de Biologia, Universidade Estadual de Montes Claros, Vila Mauricéia, CEP 39401-089, Montes Claros (MG), Brasil. santosdangelo@gmail.com

4 Engenheira Florestal, Msc., Professora do Departamento de Ciências Florestais, Instituto de Ciências Agrárias, Universidade Federal de Mina Gerais, Av. Universitária, 1000, Bairro Universitário, CEP 39404-006, Montes Claros (MG), Brasil. dora.mapf@bol.com.br

Recebido para publicação em 9/04/2010 e aceito em 11/09/2012 


\section{INTRODUÇÃO}

O Estado de Minas Gerais apresenta riqueza de formações vegetais, constituindo um complexo mosaico, devido as suas diversas condições geológicas, topográficas e climáticas (MELLO-BARRETO, 1942 e COSTA et al., 1998). Entre estas formações, estão presentes o cerrado e a caatinga com suas várias fitofisionomias (SANO e ALMEIDA, 1998). Atualmente, sua cobertura vegetal está drasticamente reduzida a remanescentes esparsos. Estudo realizado pelo CETEC (1993) concluiu que, atualmente, a área ocupada pelas florestas nativas não chega a $2 \%$ do território mineiro. O processo de ocupação desordenado de sua vegetação tem provocado crescente perda de diversidade biológica (OLIVEIRA-FILHO e MACHADO, 1993).

As florestas ciliares também foram extremamente degradadas no estado (VILELA et al., 1994). Essas formações vegetais são sistemas particularmente frágeis em face dos impactos promovidos pelo homem, localizam-se em áreas onde, comumente, ocorrem os solos mais férteis e úmidos. Por isso, estas áreas são tão propensas a derrubadas, dando lugar às atividades agrícolas, colocando em risco a diversidade das faunas aquática e silvestre (BOTELHO e DAVIDE, 2002; OLIVEIRA-FILHO et al., 1994; VAN DEN BERG, 1995). Do ponto de vista ecológico, as florestas ciliares se destacam pela riqueza de espécies (FELFILI et al., 2001) sendo consideradas como corredores ecológicos para a movimentação da fauna e para a dispersão vegetal, exercendo importante papel na proteção de recursos hídricos (LIMA e ZAKIA, 2000).

O conhecimento da composição florística das florestas ciliares é um pré-requisito importante para projetos de recomposição da cobertura vegetal de áreas marginais a rios, córregos e nascentes (SILVA et al., 1995); entretanto, estudos sobre a ecologia desse ecossistema são ainda escassos no Norte de Minas Gerais, de acordo com Santos e Vieira (2005), a vegetação desta região possui características peculiares e ainda é muito pouco estudada.

O Norte de Minas Gerais, especificamente a região de Montes Claros, está inserido em uma área de transição entre os domínios do Cerrado e da Caatinga (SANO e ALMEIDA, 1998). Em graus distintos, nota-se a dominância de uma formação sobre a outra, dando origem a fitofisionomias bem distintas, considerando o porte dos indivíduos e a composição das espécies (SANTOS et al., 2007). Entre as fitofisionomias encontradas nesses ecótonos, uma das mais características é a mata seca, referida na classificação do IBGE, como Floresta Estacional Decidual (VELOSO et al., 1991), vegetação que possui estrutura e composição florística muito variadas (PEDRALLI, 1997).

Adicionalmente às "matas secas", nessa região ocorrem as florestas ciliares, que, de acordo com Ribeiro e Walter (1998), são perenifólias e floristicamente similares à mata seca, sendo a transição entre estas praticamente imperceptível na região, diferenciando-se pela estrutura, que em geral é mais densa e mais alta e pela associação ao curso de água.

As evidências apontadas com relação à importância biológica e necessidade de conservação destas formações, não são suficientes para sua preservação. A vegetação ciliar do Rio Cedro sofre com a derrubada e a queima para atividades de plantio e para formação de pastagens, como consequência estas áreas estão reduzidas a fragmentos esparsos, com intenso grau de antropização. O que torna crítico esse fato é a carência de pesquisa sobre esse ecossistema. Dessa forma, o presente estudo teve como objetivo determinar a composição florística de três fragmentos de floresta ciliar do Rio Cedro, importante como subsídio à seleção de espécies para sua recomposição ciliar, fazendo parte integrante do Projeto Mãe D’Água: Revitalização da Bacia do Rio Cedro em Montes Claros, MG.

\section{MATERIAL E MÉTODOS}

\section{Área de Estudo}

O Rio Cedro tem nascente em Montes Claros, Norte de Minas Gerais (Figura 1), possui área total de $55,14 \mathrm{Km}^{2}$ e é o maior afluente do Rio Vieira, tributário do Rio Verde Grande, este por sua vez, integra a bacia do Rio São Francisco. Fisionomicamente, a região está incluída na transição dos domínios do Cerrado e da Caatinga, apresentando como fisionomia predominante na área de estudo a Floresta Estacional Decidual (RIZZINI, 1997; NUNES et al., 2005). O clima da região, segundo a classificação de Köppen, é o Aw: tropical de savana, inverno seco e verão chuvoso, com temperatura media anual de $24,1{ }^{\circ} \mathrm{C}$ e precipitação média anual variando de 1.000 a $1.100 \mathrm{~mm}$ (SANTOS et al., 2007).

\section{Composição Florística}

Para o estudo do perfil florístico do Rio Cedro, foram selecionados três trechos consecu- 


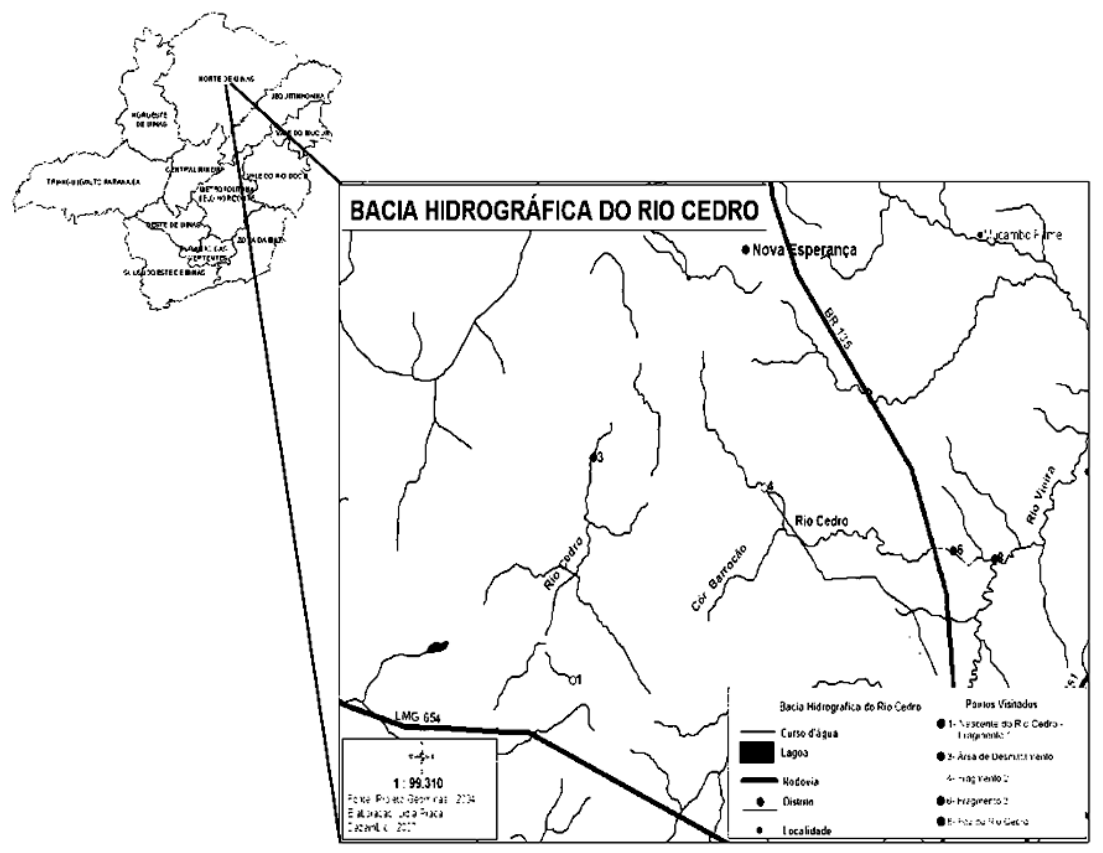

FIGURA 1: Mapa da Bacia Hidrográfica do Rio Cedro, Montes Claros - MG.

FIGURA 1: 'Cedro' River watershed management, Montes Claros - MG state.

tivos de floresta ciliar, denominados: Fragmento 1, coordenadas 23K 0605384808154572 UTM, com área de 0,3ha; Fragmento 2, coordenadas $23 \mathrm{~K}$ 06071558158284 UTM, com 3,3ha e Fragmento 3, coordenadas 23K 6182788157226 UTM, com $1,2 \mathrm{ha}$. Os fragmentos escolhidos foram os que apresentaram melhor estado de conservação. O levantamento das espécies foi realizado no período de setembro e novembro de 2007, utilizando o método do Caminhamento; método expedito para levantamentos florísticos (FILGUEIRAS et al., 1994), que consiste basicamente na descrição sumária da vegetação da área a ser amostrada, listando-se as espécies. A identificação da vegetação arbórea nas áreas ciliares processou-se por caminhadas aleatórias nas margens direita e esquerda de cada fragmento, com duração de 1 hora cada. Foram anotadas todas as espécies, pertencentes a indivíduos arbóreos com DAP (diâmetro a altura do peito igual ou superior a $10 \mathrm{~cm}$ ). A identificação das espécies deu-se através da consulta a especialistas e à bibliografia especializada. A delimitação das famílias segue o Sistema de Classificação do APG, Angiosperm Phylogeny Group II (2003).

\section{Classificação ecofisiológica}

As espécies foram distribuídas em três grupos sucessionais: pioneiras, secundárias iniciais e secundárias tardias, tomando-se por base os trabalhos realizados por Gandolfi et al. (1995), Paula et al. (2004) e Tabarelli e Mantovani (1997) além de observações no campo sobre o comportamento das espécies, já que a classificação deve se adaptar à realidade local. As espécies que não são citadas na literatura consultada estão sem classificação.

\section{Análise de Similaridade}

Para quantificar a similaridade florística entre os três fragmentos e, entre o presente estudo e outros levantamentos florísticos realizados no estado de Minas Gerais, foi utilizado o índice de similaridade de Sørensen (MÜELLER-DOMBOIS e ELLENBERG, 1974) por meio da seguinte expressão: $\mathrm{IS}=(2 \mathrm{C} / \mathrm{A}+\mathrm{B}) \mathrm{X} 100$, em que: $\mathrm{C}=$ números de espécies comuns às duas comunidades confrontadas; $\mathrm{A}=$ número total de espécies na comunidade $\mathrm{A}$ e $\mathrm{B}=$ número total de espécies na comunidade $\mathrm{B}$.

\section{RESULTADOS E DISCUSSÃO}

\section{Composição Florística}

Foi amostrado um total de 356 indivíduos em três fragmentos, sendo: 99 no $1^{\circ}$ Fragmento, 117 no $2^{\circ}$ Fragmento e 140 no $3^{\circ}$ Fragmento, sendo este último o que apresentou uma maior abun- 
dância de indivíduos. No levantamento florístico dos fragmentos foram identificados um total de 53 espécies, sendo duas espécies de Fabaceae não identificadas, e 46 gêneros de 22 famílias. A maior riqueza florística foi encontrada no $1^{\circ}$ Fragmento, com 28 espécies, seguido pelo $2^{\circ}$ Fragmento com 26 e o $3^{\circ}$ Fragmento com 25 espécies (Tabela 1 ). As famílias que apresentaram maior número de indivíduos foram: Fabaceae (111), Malvaceae (50), Arecaceae (45) e Anacardiaceae (32). Fabaceae contribuiu com 18 espécies, seguida por Anacardiaceae com três, Malvaceae com dois, e Arecaceae com uma espécie. Essas quatro famílias correspondem a $66,8 \%$ das espécies identificadas, enquanto que as outras 18 famílias dividem as $33,2 \%$ restantes (Figura 2).

TABELA 1: Número de indivíduos e grupo ecológico das espécies amostradas nos três fragmentos de floresta ciliar do Rio Cedro, Montes Claros - MG.

TABELA 1: Numbers of individuals and ecological group of sampled species of three fragments of the riparian forest from 'Cedro River', Montes Claros - MG state.

\begin{tabular}{|c|c|c|c|c|}
\hline \multirow{2}{*}{ Família/Espécie } & \multirow{2}{*}{ GE } & \multicolumn{3}{|c|}{ Número de indivíduos } \\
\hline & & $1^{\circ}$ Fragmento & $2^{\circ}$ Fragmento & $3^{\circ}$ Fragmento \\
\hline \multicolumn{5}{|l|}{ ANACARDIACEAE } \\
\hline Mangifera indica $\mathrm{L}$. & Scla & - & - & 02 \\
\hline Myracrodruon urundeuva Fr. All. & SI & 03 & 17 & 03 \\
\hline Schinopsis brasiliensis Engl. & SI & & 07 & - \\
\hline \multicolumn{5}{|l|}{ APOCYNACEAE } \\
\hline Aspidosperma pyrifolium Mart. & Scla & - & 03 & - \\
\hline Aspidosperma tomentosum Mart. & Scla & 03 & - & - \\
\hline Peschiera sp & SI & - & 03 & - \\
\hline \multicolumn{5}{|l|}{ ARALIACEAE } \\
\hline $\begin{array}{l}\text { Dendropanax cuneatus (DC.) Decne \& Planchon } \\
\text { ARECACEAE }\end{array}$ & SI & - & - & 08 \\
\hline $\begin{array}{l}\text { Acrocomia aculeata (Jacq.) Lodd. X } \\
\text { ASTERACEAE }\end{array}$ & $\mathrm{P}$ & 05 & 02 & 38 \\
\hline $\begin{array}{l}\text { Piptocarpha rotundifolia (Less.) Baker } \\
\text { CANNABACEAE }\end{array}$ & $\mathrm{P}$ & - & 03 & - \\
\hline $\begin{array}{l}\text { Celtis iguanaea (Jacquin) Sargent } \\
\text { COMBRETACEAE }\end{array}$ & $\mathrm{P}$ & 01 & 10 & - \\
\hline Buchenavia tomentosa Eichler & Scla & - & 01 & - \\
\hline Combretum leprosum Mart. & $\mathrm{P}$ & - & 01 & - \\
\hline $\begin{array}{l}\text { Terminalia argêntea Mart. ET Succ } \\
\text { CHRYSOBALANACEAE }\end{array}$ & SI & 01 & - & - \\
\hline Hirtella glandulosa Spreng. & ST & 01 & - & 04 \\
\hline $\begin{array}{l}\text { Hirtella gracilipes (Hook. f.) Prance } \\
\text { EUPHORBIACEAE }\end{array}$ & Scla & - & - & - \\
\hline Croton urucurana Baill. & $\mathrm{P}$ & - & 13 & 05 \\
\hline Sapium obovatum Müll.Arg. & Scla & - & 02 & - \\
\hline \multicolumn{5}{|l|}{ FABACEAE } \\
\hline Acacia polyphylla DC. & SI & - & 01 & - \\
\hline Anadenanthera colubrina (Vell.)Brenan & SI & 03 & 10 & - \\
\hline Bowdichia virgilioides H. B. \& K. & ST & 01 & - & - \\
\hline $\begin{array}{l}\text { Chloroleucon tenuiflorum (Benth.) Barneby \& } \\
\text { J.W.Grimes }\end{array}$ & Scla & - & - & 07 \\
\hline Deguelia costata (Benth.) Az. Tozzi & Scla & & - & 04 \\
\hline Enterolobium contortisiliquum (Vell.) Morong. & SI & 2 & 09 & 07 \\
\hline
\end{tabular}


TABELA 1: Continuação ...

TABELA 1: Continued ...

\begin{tabular}{|c|c|c|c|c|}
\hline \multirow{2}{*}{ Família/Espécie } & \multirow{2}{*}{ GE } & \multicolumn{3}{|c|}{ Número de indivíduos } \\
\hline & & $1^{\circ}$ Fragmento & $2^{\circ}$ Fragmento & $3^{\circ}$ Fragmento \\
\hline \multicolumn{5}{|l|}{ FABACEAE } \\
\hline Hymenaea stigonocarpa Mart. ex Hayne & ST & 02 & 02 & - \\
\hline Hymenaea courbaril L. & ST & - & - & 01 \\
\hline Inga sessilis (Vell.) Mart. & SI & 05 & 01 & 08 \\
\hline Lonchocarpus sericeus (Poir.) Kunthex.DC. & Scla & 02 & 01 & 05 \\
\hline Machaerium aculeatum Raddi & $\mathrm{P}$ & - & 02 & - \\
\hline Machaerium scleroxylon Tul. & Scla & 02 & - & - \\
\hline Piptadenia viridiflora (Kunth) Benth. & Scla & - & - & 01 \\
\hline Platypodium elegans Vog. & SI & 02 & 02 & - \\
\hline Platymiscium floribundum Vog. & Scla & - & 01 & 01 \\
\hline Pterogyne nitens Tul. & SI & - & - & 01 \\
\hline Não identificada 1 & Scla & 06 & - & - \\
\hline Não identificada 2 & Scla & 01 & - & - \\
\hline \multicolumn{5}{|l|}{ LAURACEAE } \\
\hline Nectandra SP & Scla & - & - & 04 \\
\hline \multicolumn{5}{|l|}{ LECYTHIDACEAE } \\
\hline Cariniana estrellensis (Raddi) Kuntze & ST & 01 & 01 & - \\
\hline \multicolumn{5}{|l|}{ MALVACEAE } \\
\hline Guazuma ulmifolia Lam. & $\mathrm{P}$ & 18 & 20 & 10 \\
\hline Luehea divaricata Mart. & SI & 01 & 01 & - \\
\hline \multicolumn{5}{|l|}{ MELIACEAE } \\
\hline Guarea kunthiana A.Juss. & SI & 05 & - & 09 \\
\hline \multicolumn{5}{|l|}{ MORACEAE } \\
\hline Fícus SP & Scla & 02 & - & 08 \\
\hline Fícus calyptroceras (Miq.)Miq. & ST & - & - & 03 \\
\hline Maclura tinctoria D. Don ex Steud & SI & 02 & - & - \\
\hline \multicolumn{5}{|l|}{ MYRTACEAE } \\
\hline Eugenia florida DC. & SI & 01 & - & - \\
\hline Myrciaria cauliflora (Mart.) O. Berg & Scla & 01 & - & - \\
\hline Psidium guajava $\mathrm{L}$. & $\mathrm{P}$ & - & 01 & 01 \\
\hline \multicolumn{5}{|l|}{ OPILIACEAE } \\
\hline \multicolumn{5}{|l|}{ RHAMNACEAE } \\
\hline Rhamnidium elaeocarpum Reiss. & $\mathrm{P}$ & 02 & - & - \\
\hline \multicolumn{5}{|l|}{ RUBIACEAE } \\
\hline Genipa americana $\mathrm{L}$. & ST & - & - & 02 \\
\hline \multicolumn{5}{|l|}{ RUTACEAE } \\
\hline Zanthoxylum riedelianum Engl. & $\mathrm{P}$ & - & 02 & 05 \\
\hline \multicolumn{5}{|l|}{ SAPINDACEAE } \\
\hline Talisia esculenta (St. Hil.) Radlk. & Scla & 03 & 01 & - \\
\hline \multicolumn{5}{|l|}{ URTICACEAE } \\
\hline Cecropia pachystachya Trec. & $\mathrm{P}$ & 01 & - & 01 \\
\hline Cecropia glaziovii Snethl. & $\mathrm{P}$ & - & - & 01 \\
\hline Somatório & & 99 & 117 & 140 \\
\hline
\end{tabular}

Em que: $\mathrm{GE}$ = grupo ecológico; $\mathrm{P}$ = pioneira; $\mathrm{Si}$ = secundária inicial; $\mathrm{ST}$ = secundária tardia; $\mathrm{Scla}=$ sem classificação. 


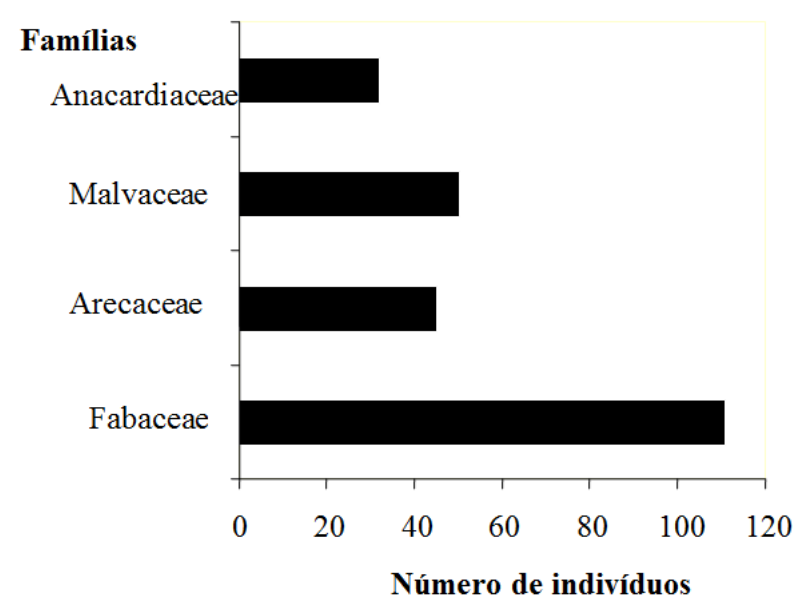

FIGURA 2: Famílias com maior número de indivíduos amostrados no levantamento florístico em três fragmentos de floresta ciliar do Rio Cedro, Montes Claros - MG.

FIGURA 2: Families with highest number of individuals as shown in the three fragments of the riparian forest from 'Cedro' River floristic survey, Montes Claros - MG state.

Fabaceae foi a família mais representativa floristicamente e amplamente distribuída pelos três fragmentos. Estes mesmos resultados têm sido encontrados em estudos florísticos em áreas de floresta ciliar do Brasil Central (VAN DEN BERG e OLIVEIRA-FILHO, 2000; AZEVEDO et al., 2008; MEYER et al., 2004) demonstrando a grande distribuição e poder adaptativo desta família a diversos tipos de solo e clima. Fabaceae desempenha importante papel ecológico em ecossistemas ciliares, e sua presença marcante no perfil florístico do Rio Cedro, demonstra que a comunidade vegetal, não foge ao padrão característico das florestas ciliares da região sudeste. A abundância expressiva e a ampla distribuição da família Fabaceae, pela sua capacidade de fixação do nitrogênio atmosférico, favorecem o processo de sucessão e o surgimento de espécies mais exigentes, apresentando potencial para implantação como facilitadora da sucessão (CARPANEZZI, 2005) e, portanto, tem importante papel na recomposição da vegetação do Rio Cedro,

As espécies mais abundantes no $1^{\circ}$ Fragmento foram Enterolobium contortisiliquum (22) e Guazuma ulmifolia (18), no $2^{\circ}$ Fragmento foram mais abundantes a Guazuma ulmifolia (20),
Myracrodruon urundeuva (17) e no $3^{\circ}$ Fragmento as espécies mais abundantes foram Acrocomia aculeata (38) e Guazuma ulmifolia (10).

Arecaceae esteve amplamente distribuída nos três fragmentos, constituindo a família com abundância de indivíduos representados por uma única espécie, Acrocomia aculeata, demonstrando se tratar de um caso de dominância, em especial no $3^{\circ}$ Fragmento que obteve a maior número de indivíduos desta espécie. O predomínio em número desta espécie na comunidade é tido por Richards (1952) como dominância ecológica, fato de ocorrência comum em florestas tropicais.

Mota et al. (2002) associam o avanço das espécies de palmeiras nas áreas onde as atividades antrópicas foram realizadas no passado e hoje foram abandonadas, como por exemplo, áreas de pastagens. E ainda, Lorenzi (1992) ressalta a ocorrência preferencial de Acrocomia aculeata em vales e encostas como ocorre no $3^{\circ}$ Fragmento, onde a floresta ciliar se situa em uma depressão, circundada por área de pastagem.

As espécies Myracrodruon urundeuva, Anadenanthera colubrina, Schinopsis brasiliensis e Guazuma ulmifolia estiveram representadas nos fragmentos, e são, de acordo com Pedralli (1997) e Mendonça et al. (1998), espécies típicas da Floresta Estacional Decidual, que é a formação vegetal adjacente à floresta ciliar do Rio Cedro. De acordo com Ribeiro e Walter (1998), uma importante peculiaridade das florestas ciliares é a sua interface com as formações vegetais vizinhas, as quais em geral contribuem para a sua riqueza florística. A influência da Floresta Estacional Decidual na composição florística da vegetação ciliar também foi constatada por Santos e Vieira (2006) em área próxima ao Rio Cedro. No estudo, os pesquisadores identificaram a ocorrência destas mesmas espécies, demonstrando a influência desta fitofisionomia na formação e heterogeneidade destes ecossistemas.

Além de espécies típicas da floresta estacional decidual, ocorreram também nos fragmentos, as espécies características de floresta ciliar: Inga sessilis (Vell.) Mart., Celtis iguanaea (Jacquin) Sargent, Talisia esculenta (St. Hil.) Radlk., Croton urucurana Baill.e Cecropia pachystachya Trec. citadas na literatura com ocorrência relacionada a cursos d'água ou em áreas de elevado teor de umidade (MENDONÇA et al., 1998 e PINTO e OLIVEIRA-FILHO, 1999 e LORENZI, 2000). 


\section{Grupos Ecofisiológicos}

No que concerne aos grupos ecofisiológicos, do total de 53 espécies encontradas nos três fragmentos, 12 espécies foram classificados como pioneiras, 15 como secundárias iniciais e oito como secundárias tardias. As demais espécies amostradas não tiveram sua classificação encontrada na literatura consultada (Tabela 1).

As espécies pioneiras Acrocomia aculeata, Guazuma ulmifolia e as secundárias iniciais Enterolobium contortisiliquum e Myracrodruon urundeuva foram dominantes, presentes nos três fragmentos, representando as espécies com maior abundância de indivíduos. A presença marcante no perfil florístico do Rio Cedro, indica que estas espécies, são mais adaptadas ao ambiente e de acordo com Felfili et al. (2002), apresentam maior sucesso em explorar os recursos deste habitat, em relação às demais. Lorenzi (1992) salienta o pioneirismo da espécie Acrocomia aculeata (Arecaceae) em formações secundárias. E ainda, Lorenzi (2000) cita que Enterolobium contortisiliquum e Guazuma ulmifolia são espécies características de estágios mais adiantados da sucessão secundária. Bertoni e Dickfeldt (2007) citam Myracrodruon urundeuva como espécie secundária e normalmente presente em áreas antropizadas, como nos fragmentos estudados.

Do total de indivíduos, houve uma maior abundância de espécies pioneiras $(40,2 \%)$ e secundárias iniciais $(36,8 \%)$, indicando uma fase de transição da floresta pioneira, graças às novas condições ecológicas, especialmente o sombreamento, favorecendo o estabelecimento de espécies secundárias tardias. A abundância destas espécies da fase inicial da sucessão caracteriza, de acordo com Carpanezzi (2005), um típico modelo de facilitação ecológica permitindo a ocupação de espécies mais exigentes.

Foi observada em campo, a existência de grande número de clareiras e de irregularidades no dossel da floresta sugerindo, de acordo com Pinto e Oliveira-Filho (1999), tratar-se de comunidades com altos valores de recomposição turnover ou dinâmica processual. Esses valores de recomposição são comumente influenciados por altas taxas de distúrbios naturais como a formação de clareiras por queda das árvores, o que certamente pode incrementar a concentração de novos indivíduos na floresta ciliar do Rio Cedro. De acordo com Coraiola e Netto (2003), as clareiras forneceram sítios para as espécies de crescimento rápido, como as pioneiras, consideradas provável "oportunistas de clareira" que ocupam rapi- damente as aberturas naturais. Estas espécies encontraram nestes ambientes condições favoráveis para seu estabelecimento e desenvolvimento até o dossel em virtude dessas situações.

Os fragmentos estudados encontram-se perturbados em decorrência do processo de antropização. Foi observado nestes locais, o corte de árvores e a presença de bovinos e equinos. A retirada de espécies arbóreas contribui para a fragmentação florestal sujeitando estes ambientes ao efeito de borda, que, de acordo com Pinto et al. (2005), pode ter influência na distribuição das espécies. A influência antrópica na floresta ciliar do Rio Cedro causa redução de tamanho dos fragmentos e fornece condições favoráveis ao estabelecimento de espécies tolerantes nestes ambientes, o que explica a predominância de espécies do grupo ecofisiológico das pioneiras e secundárias iniciais nos três fragmentos.

\section{Análise da Similaridade}

Quanto à análise de similaridade florística, os fragmentos mais semelhantes foram respectivamente: Fragmentos 1 e 2 com um índice de similaridade de Sørensen de 49\%; Fragmentos 2 e 3 com 39,2 \%; e Fragmentos 1 e $3 \mathrm{com} 33,3 \%$. A proximidade geográfica pode ser o fator determinante na maior similaridade encontrada entre os Fragmentos 1 e 2, os quais se encontram a uma menor distância entre si, em relação ao $3^{\circ}$ Fragmento. E ainda, a semelhança florística entre estes fragmentos pode ser explicada pelo fato destas áreas ocorrerem em uma mesma região, com uma distância de $6 \mathrm{~km}$ entre os Fragmentos 1 e 2 e 18 km entre o Fragmentos 1 e 3, portanto, com altitudes e climas semelhantes (VAN DEN BERG e OLIVEIRA-FILHO, 2000).

Comparando-se as espécies amostradas no presente estudo com outros levantamentos em florestas ciliares do estado de Minas Gerais, observa-se que os Índices de Similaridade de Sørensen variaram entre $4,7 \%$ e $48,4 \%$ (Tabela 2 ).

Os índices de similaridade encontrados foram relativamente baixos em estudos de Vilela et al. (2000) em floresta ciliar inserida na Floresta Estacional Semidecidual $(4,7 \%)$ e em Meyer et al. (2004) realizado na Serra do Cipó (13\%). Valores intermediários foram encontrados em estudo de Azevedo et al. (2008) em um trecho de floresta ciliar inserida em área de transição entre o bioma cerrado e caatinga (22,9\%). De maneira geral, os baixos índices de similaridade encontrados entre estas áreas refletem as diferenças fitogeográficas abrangidas nos 
TABELA 2: Similaridade florística entre os fragmentos de floresta ciliar do Rio Cedro, Montes Claros, MG, e algumas florestas ciliares de Minas Gerais. N = número total de espécies encontradas; $\mathrm{NC}=$ número de espécies comuns; IS = índice de similaridade de Sørensen.

TABELA 2: Floristic similarity between the fragments of the riparian forest fom 'Cedro' River, Montes Claros, MG state, and some riparian forests from Minas Gerais state. $\mathrm{N}=$ total number of identified species; $\mathrm{NC}=$ number of common species; IS = Sørensen's similarity index.

\begin{tabular}{llccc}
\hline Local & Autor(es) & N & C & IS \\
\hline Rio Grande - Madre de Deus & Vilela et al.(2000) & 16 & 53 & $4,7 \%$ \\
Rola Moça - Belo Horizonte & Meyer et al. (2004) & 97 & 10 & $13 \%$ \\
Rio Pandeiros - Norte de Minas & Azevedo et al. (2008) & 13 & 19 & $22,9 \%$ \\
Parque Sapucaia - Montes Claros & Santos e Vieira (2006) & 2 & 23 & $48,4 \%$ \\
\hline
\end{tabular}

estudos, solos e clima distintos. Soma-se, ainda, o fato das florestas ciliares, geralmente, apresentarem altos índices de diversidade, o que muitas vezes é influenciado pela vegetação adjacente (OLIVEIRAFILHO et al., 1994).

As formações estudadas por Santos e Vieira (2006) obtiveram valores maiores de similaridade com a floresta ciliar do Rio Cedro (48,4\%). Segundo Matteucci e Colma (1982), valores acima de 25\% indicam similaridade florística, o que leva a supor certa uniformidade em relação a estas áreas, que recebem influência da floresta estacional decidual. Provavelmente, as semelhanças encontradas para essas florestas pode ser devido à proximidade geográfica destas áreas, condição de clima e características edáficas semelhantes, bem como à influência do domínio vegetacional em que estão inseridas.

\section{Espécies Indicadas para a Recomposição da Floresta Ciliar}

As espécies selecionadas para a recomposi- ção da floresta ciliar do Rio Cedro, Montes ClarosMG foram aquelas identificadas no levantamento florístico, de acordo com a recomendação de Barbosa e Martins (2007), priorizando espécies do próprio ecossistema, garantindo assim a conservação da diversidade regional. Foram indicadas as espécies mais abundantes e ainda aquelas com ampla distribuição pelos fragmentos, considerando que a presença de uma espécie num determinado ambiente, indica a sua adaptação às condições locais, dando preferência para as espécies atrativas da fauna, que, de acordo com Andrade (2003), são importantes na manutenção de interações ecológicas dentro do ecossistema.

As espécies a serem utilizadas na recomposição do Rio Cedro serão aquelas de diferentes grupos sucessionais, que darão suporte para a restauração da função ecológica da floresta ciliar. Estas espécies foram agrupadas de acordo com sua preferência de solos bem drenados, ou solos úmidos/encharcados, segundo metodologia descrita por Pinto et al. (2005) e observações em campo (Tabela 3).

TABELA 3: Relação de espécies com potencial para utilização na recomposição do Rio Cedro, Montes Claros, MG.

TABELA 3: List of species with potential to be used in 'Cedro' River restoration, Montes Claros, MG state.

\begin{tabular}{lccc}
\hline Família/Espécie & Nome Popular & GE & $\begin{array}{c}\text { Grupos para } \\
\text { Recomposição }\end{array}$ \\
\hline ANACARDIACEAE & Aroeira & SI & 2 \\
$\begin{array}{l}\text { Myracrodruon urundeuva Fr. All. } \\
\text { Schinopsis brasiliensis Engl. }\end{array}$ & Pau-preto & SI & 2 \\
ARECACEAE & & & \\
Acrocomia aculeata (Jacq.) Lodd. X & Macaúba & P & 1,2 \\
\hline
\end{tabular}


TABELA 3: Continuação ...

TABELA 3: Continued ...

\begin{tabular}{|c|c|c|c|}
\hline Família/Espécie & Nome Popular & GE & $\begin{array}{l}\text { Grupos para } \\
\text { Recomposição }\end{array}$ \\
\hline \multicolumn{4}{|l|}{ CECROPIACEAE } \\
\hline Cecropia pachystachya Trec. & Embaúba & $P$ & 1 \\
\hline Cecropia glaziovii Snethl. & & $\mathrm{P}$ & 1 \\
\hline \multicolumn{4}{|l|}{ CANNABACEAE } \\
\hline Celtis iguanaea (Jacquin) Sargent & & $\mathrm{P}$ & 1 \\
\hline \multicolumn{4}{|l|}{ EUPHORBIACEAE } \\
\hline Croton urucurana Baill. & Sangra-d'água & $\mathrm{P}$ & 1 \\
\hline \multicolumn{4}{|l|}{ FABACEAE } \\
\hline Acacia polyphylla DC. & & SI & 1 \\
\hline Anadenanthera colubrina (Vell.)Brenan & Angico-vermelho & SI & 1,2 \\
\hline Bowdichia virgilioides H. B. \& K. & Sucupira & ST & 2 \\
\hline Enterolobium contortisiliquum (Vell.) Morong. & Tamboril & SI & 1,2 \\
\hline Hymenaea stigonocarpa Mart. ex Hayne & Jatobá & ST & 1,2 \\
\hline Hymenaea courbaril L. & & ST & 1,2 \\
\hline Inga sessilis (Vell.) Mart. & Ingazeiro & SI & 1 \\
\hline Machaerium aculeatum Raddi & & $\mathrm{P}$ & 1,2 \\
\hline Platypodium elegans Vog. & Jacarandá & SI & 2 \\
\hline Platymi floribundum Vog. & Tamboril-de-baixada & Scla & 1,2 \\
\hline Pterogyne nitens Tul. & & SI & 1,2 \\
\hline \multicolumn{4}{|l|}{ MALVACEAE } \\
\hline Guazuma ulmifolia Lam. & Mutambeira & $\mathrm{P}$ & 1 \\
\hline Luehea divaricata Mart. & Açoita-cavalo & SI & 1,2 \\
\hline \multicolumn{4}{|l|}{ MELIACEAE } \\
\hline Guarea kunthiana A.Juss. & & SI & 1 \\
\hline \multicolumn{4}{|l|}{ MORACEAE } \\
\hline Ficus calyptroceras (Miq.)Miq. & & ST & 1 \\
\hline Maclura tinctoria D. Don ex Steud & & SI & 1,2 \\
\hline \multicolumn{4}{|l|}{ MYRTACEAE } \\
\hline Eugenia florida DC. & Cagaiteira & SI & 2 \\
\hline Myrciaria cauliflora (Mart.) O. Berg & Jabuticabeira & Scla & 1,2 \\
\hline Psidium guajava $\mathrm{L}$. & Goiabeira & $\mathrm{P}$ & 1,2 \\
\hline \multicolumn{4}{|l|}{ OPILIACEAE } \\
\hline $\begin{array}{l}\text { Agonandra brasiliensis Miers ex Benth. \& Hook. F. } \\
\text { RUBIACEAE }\end{array}$ & Cervejinha & ST & 1 \\
\hline Genipa americana $\mathrm{L}$. & Genipapo & ST & 1 \\
\hline \multicolumn{4}{|l|}{ SAPINDACEAE } \\
\hline Talisia esculenta (St. Hil.) Radlk. & Pitombeira & Scla & 1 \\
\hline
\end{tabular}

Em que: GE = grupo ecológico, grupos para recomposição: 1 = espécies típicas de solos úmidos ou encharcados e 2 $=$ espécies típicas de solos bem drenados. Grupos ecológicos: $\mathrm{P}=$ Pioneira; $\mathrm{SI}=$ Secundária Inicial; $\mathrm{ST}=$ Secundária Tardia e Scla = Sem classificação. 


\section{CONCLUSÕES}

Os fragmentos de floresta ciliar do Rio Cedro têm contribuição de espécies da Floresta Estacional Decídua, demonstrado a grande influência desta formação vegetal limítrofe na composição florística.

Os fragmentos estudados encontram-se perturbados em decorrência dos processos de antropização e em estágio sucessional médio, com dominância de espécies pioneiras e secundárias iniciais.

Todas as espécies levantadas no presente estudo são potenciais para a recomposição ciliar, entretanto, recomenda-se que sejam utilizadas principalmente espécies mais adaptadas às condições dos sítios locais.

Os Fragmentos 1 e 2 possuem maior similaridade florística. A proximidade geográfica, as condições de clima e altitudes semelhantes podem ser o fator determinante na maior similaridade encontrada.

\section{REFERÊNCIAS BIBLIOGRÁFICAS}

ANDRADE, M. A. Arvores zoocóricas como núcleos de atração de avifauna e dispersão de sementes. 2003. 91 f. Dissertação (Mestrado em Engenharia Florestal) - Universidade Federal de Lavras, Lavras, 2003.

APG (Angiosperm Phylogeny Group) II. An update of the Angiosperm Phylogeny Group classification for the orders and families of flowering plants: APG II. Botanical Journal of the Linnean Society, Londres, v. 141, p. 399-436, 2003.

AZEVEDO, I. F. P. et al. Composição Florística da Comunidade Arbórea de um trecho da mata ciliar do Rio Pandeiros, Norte de Minas. In: SIMPOSIO NACIONAL CERRADO, 9., 2008, Brasília. Anais... Brasília: Parla Mundi, 2008.

BARBOSA, L. M.; MARTINS, S. E. Espécies arbóreas nativas: indicação por região e ecossistema do Estado de São Paulo. São Paulo: Instituto de Botânica. Disponível em: (http://www. ibot.sp.gov.br/especie arborea/ especies arboreas. html). Acesso em: 30 julho 2007.

BOTELHO, S. A.; DAVIDE, A. C. Métodos silviculturais para recuperação de nascentes e recomposição de matas ciliares. In: SIMPÓSIO NACIONAL SOBRE RECUPERAÇÃO DE ÁREAS DEGRADADAS, 5., 2002, Belo Horizonte. Anais... Belo Horizonte: 2002, p. 123-145.

BERTONI, J. E. A.; DICKFELDT, E. P. Plantio de Myracrodruon urundeuva Fr. All. (aroeira) em área alterada de floresta: Desenvolvimento das mudas e restauração florestal. Revista do Instituto Florestal, São Paulo, v. 19, n. 1, p. 31-38, 2007.

CARPANEZZI, A. A. Fundamentos para a reabilitação de ecossistemas florestais. In: GALVÃO, A. P. M.; PORFÍRIO-DA-SILVA, V. (Orgs.) Restauração Florestal: Fundamentos e Estudos de Caso. Colombo: EMBRAPA/Florestas, 2005. p. 2745.

CETEC - Fundação Centro Tecnológico de Minas Gerais. Desenvolvimento de metodologia para recuperação do revestimento florístico natural em áreas de proteção das captações de água da COPASA na Região Metropolitana de Belo Horizonte. Belo Horizonte: SAT/CETEC, 1993. 83 p. (Relatório técnico).

CORAIOLA, M.; NETTO, S. P. Análise da Estrutura Horizontal e uma Floresta Estacional Semidecidual localizada no Município de Cássia - MG. Revista Acadêmica: ciências agrárias e ambientais, São José dos Pinhais, v. 1, n. 2, p. 11-19, 2003.

COSTA, C. M. R. et al. Biodiversidade em Minas Gerais: um Atlas para sua conservação. Belo Horizonte: Fundação Biodiversitas, 1998. 94 p.

FILGUEIRAS, T. S. et al. Caminhamento - um método expedito para levantamentos florísticos qualitativos. Cadernos de Geociências IBGE, Rio de Janeiro, v. 12, n. 4, p.39 - 43, 1994.

FELFILI, J. M. et al. Desenvolvimento inicial de espécies de Mata de Galeria. In: RIBEIRO, J. F.; FONSECA, C. E. L.; SOUSA-SILVA, J. C. Cerrado: caracterização e recuperação de matas de galeria. Planaltina: EMBRAPA/Cerrados, 2001. p. 779-811.

FELFILI, J. M. et al. Composição florística e fitossociológica do cerrado sentido restrito no município de Água Boa-MT. Acta Botanica Brasilica, Brasília,v. 16, n. 1, p. 103-112, 2002.

GANDOLFI, S. et al. Levantamento florístico e caráter sucessional das espécies arbustivo arbóreas de uma floresta mesófila semidecidua no município de Guarulhos, SP. Revista Brasileira de Biologia, Rio de Janeiro, v. 55, n. 4, p. 753-767,1995.

LIMA, W. P.; ZAKIA, M. J. B. Hidrologia de matas ciliares. In: Matas ciliares: conservação e recuperação. RODRIGUES, R. R.; LEITÃOFILHO, H. F. (eds.). São Paulo: EDUSP, 2000. p. 33-44.

LORENZI, H. Árvores brasileiras: manual de identificação e cultivo de plantas arbóreas nativas do Brasil. 1 ed. Nova Odessa: Editora Plantarum, 
1992. $352 \mathrm{p}$.

LORENZI, H.. Árvores Brasileiras: manual de identificação e cultivo de plantas arbóreas nativas do Brasil. 2 ed. Nova Odessa: Editora Plantarum, 2000. 352 p.

MATTEUCCI, S.D.; COLMA,A. Metodologia para el estudio de la vegetacion. Washington, Secretaria General de la Organización de los Estados Americanos. 1982.

MENDONÇA, R. C. et al. Flora vascular do Cerrado. In: SANO, S. M.; ALMEIDA, S. P. Cerrado: ambiente e flora. Planaltina: EMBRAPA/ Cerrados, 1998. p. 47-86.

MEYER, S. T. et al. Composição Florística da Vegetação arbórea de um trecho de floresta de galeria do Parque Estadual do Rola-Moça na Região Metropolitana de Belo Horizonte, MG, Brasil. Acta Botanica Brasilica, Brasília, v. 18, n. 4, p. 701709, 2004.

MELLO-BARRETO, H. L. Regiões Fitogeográficas de Minas Gerais. 1942. 14-28 p. (Boletim Geográfico, 14).

MOTTA, P. E. F. et al. Ocorrência da macaúba em Minas Gerais: relação com atributos climáticos, pedológicos e vegetacionais. Pesquisa agropecuaria brasileira, Brasília, v. 37, n. 7, p. 1023-1031, jul. 2002.

MUELLER-DOMBOIS, D.; ELLENBERG, H. Aims and methods of vegetation ecology. New York: John Wiley \& Sons, 1974. 547 p.

NUNES, Y. R. F. et al. Atividades Fenológicas de Guazuma ulmifolia Lam (Malvaceae) em uma Floresta Estacional Decidual no Norte de Minas Gerais. Lundiana, Belo Horizonte, v. 6, n. 2, p. 99105, 2005.

OLIVEIRA-FILHO, A.T. et al. Estrutura fitossociologica e variáveis ambientais em um trecho de mata ciliar do córrego dos Vilas Boas, Reserva Biológica do Poço Bonito, Lavras (MG). Revista Brasileira de Botânica, São Paulo, v. 17, n. 1, p. 67-85, 1994.

OLIVEIRA-FILHO, A.T.; MACHADO, J. N. M. Composição Florística de uma floresta semidecídua montana, na Serra de São José, Tiradentes, Minas Gerais. Acta Botanica Brasilica, Brasília, v. 7, n. 2, p. 71-88, 1993.

PAULAA. P. et al. Sucessão ecológica da vegetação arbórea em uma Floresta Estacional Semidecidual, Viçosa, MG, Brasil. Acta Botanica Brasílica, Brasília, v. 18, n. 3, p. 407-423, 2004.

PEDRALLI, G. Florestas secas sobre afloramento de calcário em Minas Gerais: Florística e fisionomias.
Revista BIOS, Cadernos do departamento de Ciências Biológicas da PUC Minas, Belo Horizonte, v. 5, p. 81-88, 1997.

PINTO, J. R. R.; OLIVEIRA-FILHO, A.T. Perfil florístico e estrutura de uma floresta de vale no Parque Nacional da Chapada dos Guimarães, Mato Grosso, Brasil. Revista Brasileira de Botânica, São Paulo, v. 22, n. 1, p. 53-67, 1999.

PINTO, L. V. A. et al. Estudo da vegetação como subsídios para propostas de recuperação das nascentes da bacia hidrográfica do ribeirão Santa Cruz, Lavras, MG. Revista Árvore, Viçosa, v. 29, n. 5, p.775 -793. 2005.

RIBEIRO, J. F.; WALTER, B. M. T. As matas de galeria no contexto do bioma Cerrado. In: SANO, S.M.; ALMEIDA, S. P. Cerrado: Ambiente e flora. Planaltina: EMBRAPA/Cerrados, 1998. p. 89-166. RICHARDS, P. W. Tropical rain forest. Cambridge: Cambridge Univ. Press, 1952. 450 p.

RIZZINI, C. T. Tratado de fitogeografia do Brasil: aspectos ecológicos, sociológicos e florísticos. 2. ed. Rio de Janeiro: Âmbito Cultural, 1997. 747 p.

SANO, S. M.; ALMEIDA, S. P. Cerrado: Ambiente e flora. Planaltina: EMBRAPA/Cerrados, 1998. $556 \mathrm{p}$.

SANTOS, R. M.; VIEIRA, F. A. Estrutura e florística de um trecho de mata ciliar do rio Carinhanha no extremo Norte de Minas Gerais, Brasil. Revista Científica Eletrônica de Engenharia Florestal., v. 5, p. 1-13. 2005.

SANTOS, R. M.; VIEIRA, F. A. Similaridade Florística entre Formações de Mata Seca e Mata de Galeria no Parque Municipal da Sapucaia, Montes Claros, MG. Revista Científica Eletrônica de Engenharia Florestal., v. 4, n. 7, 2006.

SANTOS, R. M. et al. Florística e estrutura de uma floresta estacional decidual, no Parque Municipal da Sapucaia, Montes Claros (MG). Cerne, Lavras, v. 13, n. 3, p. 248-256, 2007.

SILVA, F. C. et al. Composição florística e fitossociologia do componente arbóreo das florestas ciliares da bacia do Rio Tibagi. 3. Fazenda Bom Sucesso, Município de Sapopema, PR. Acta Botanica Brasílica, Brasília, v. 9, n. 2, p. 289-302. 1995.

TABARELLI, M.; MANTOVANI, W. Colonização de Clareiras naturais na floresta atlântica no sudeste do Brasil. Revista Brasileira de Botânica, São Paulo, v. 20, n.1, p. 57-66, 1997.

VAN DEN BERG, E. Estudo florístico e fitossociológico de uma floresta ripária em Itutinga - MG, e análise das correlações entre 
variáveis ambientais e a distribuição das espécies de porte arbóreo-arbustivo. 1995. 73 f. Dissertação (Mestrado em Ciências Florestais) - Universidade Federal de Lavras, Lavras, 1995.

VAN DEN BERG, E.; OLIVEIRA FILHO, A. T. Composição florística e fitossociologia de uma Floresta Estacional Semidecidual Montana em Itutinga, MG, e comparação com outras áreas. Revista Brasileira de Botânica, São Paulo, v. 22, n. 3, p. 231-253, 2000.

VELOSO, H. P.; RANGEL FILHO, A. L. R.; LIMA,
J. C. A. Classificação da vegetação brasileira adaptada a um sistema universal. Rio de Janeiro: IBGE, 1991.123 p.

VILELA, E. A. et al. Fitossociologia e fisionomia de mata semidecídua margeando o reservatório de Camargos em Itutinga, Minas Gerais. Ciência e Prática, Lavras, v. 18, n. 4, p. 415-424, 1994.

VILELA, E. A. et al. Caracterização estrutural de floresta ripária do Alto Rio Grande, em Madre de Deus de Minas, MG. Cerne, Lavras, v. 6, n. 2, p. 41-54, 2000. 